\title{
Is folk psychology a Lakatosian research program?
}

\section{Bill Wringe}

To cite this article: Bill Wringe (2002) Is folk psychology a Lakatosian research program?, Philosophical Psychology, 15:3, 343-358, DOI: 10.1080/0951508021000006139

To link to this article: https://doi.org/10.1080/0951508021000006139

Published online: 19 Aug 2010.

Submit your article to this journal 준

山 Article views: 38

7 Citing articles: 2 View citing articles 


\title{
Is folk psychology a Lakatosian research program?
}

\author{
BILL WRINGE
}

ABSTRACT It has often been argued, by philosophers and more recently by developmental psychologists, that our common-sense conception of the mind should be regarded as a scientific theory. However, those who advance this view rarely say much about what they take a scientific theory to be. In this paper, I look at one specific proposal as to how we should interpret the theory view of folk psychology - namely, by seeing it as having a structure analogous to that of a Lakatosian research program. I argue that although the Lakatosian model may seem promising - particularly to those who are interested in studying the development of children's understanding of the mind - the analogy between Lakatosian research programs and folk psychology cannot be made good because folk psychology does not possess anything analogous to the positive heuristic of a Lakatosian research program. I also argue that Lakatos' account of theories may not be the best one for developmental psychologists to adopt because of the emphasis which Lakatos places on the social embeddedness of scientific theorising.

\section{Introduction}

The idea that our common-sense understanding of the mind-or what philosophers call "folk psychology"-is something that it is worth comparing to a scientific theory is now commonplace. In the 1960s it was developed by enfants terribles such as Rorty (1965) and Feyerabend (1963) as a way of shaking our optimism about the epistemological status of folk psychology. In the 1970s Lewis $(1967,1970)$ exploited it in giving an account of the semantics of mental state terms and a proposed solution to the mind-body problem. In the 1980 s and 1990s it was appealed to as one possible explanation of the mechanisms underlying mental state ascription. In recent years it has been treated as a serious theoretical option by many developmental psychologists (Davies \& Stone, 1995; Gopnik \& Meltzoff, 1997).

However, despite its long pedigree there is very little agreement among its advocates as to what the claim that folk psychology is a theory actually amounts to. Those who defend the theory view (as I shall call it) rarely make explicit what it is for a given body of knowledge to constitute a theory: a fact which is both surprising

Bill Wringe, Instructor in Philosophy, Department of International Relations, Faculty of Economic, Political and Social Sciences, Bilkent University, 06533 Ankara, Turkey, email: wringe@bilkent.edu.tr or billwringe@hotmail.com 
and alarming [1]. It is surprising because one might think that the easiest way of arguing for the theory view would be to develop a plausible account of the nature of theories and then to show that folk psychology fits the account. It is alarming because in the absence of agreement as to what a theory is it is hard to be sure whether advocates and opponents of the theory view are genuinely disagreeing or just talking past one another.

In this paper I want to focus on one way of providing a detailed explication of the claim that folk psychology is a theory. This is to argue that it has a structure which is analogous to that of a Lakatosian research program. This is a view that is at least hinted at in Paul Churchland's early work on the epistemological status of folk psychology (Churchland, 1979, 1981). More recently, George Botterill (1996) has suggested that it is a version of the theory view which ought to be especially attractive to researchers who are interested in developmental issues.

Although I shall say something about the epistemological status of folk psychology towards the end of the paper, my main concern will be with theory view as it has been or might be deployed in developmental psychology. This is the area in which it is currently attracting most interest - interest which is displayed by both philosophers and psychologists (see, for example, Gopnik \& Meltzoff, 1997; PoulinDubois, 1998; Schwitzgebel, 1999; Stich \& Nicholls, 1998). It is also-as Botterill points out - an area in which Lakatosian ideas might most obviously be thought to make a useful contribution.

\section{Motivating the Lakatosian account}

Why should a Lakatosian version of the theory view of theories attract someone who is interested in developmental issues? There are two reasons. Many accounts of theoryhood which are prevalent in the literature focus on the structure of theories at particular times, and have little to say about the way in which theories develop through time. By contrast, the Lakatosian account is one which naturally allows for a focus on development. Indeed, it makes the way in which a body of knowledge develops central to the question of whether it is a scientific theory.

The Lakatosian view does well when it comes to individuating the units of study which are likely to be of interest to a developmental psychologist. Less sophisticated versions of the theory view tend to suggest that theories should be individuated by their content alone. Differences between the performance of individuals who possess the same theory then have to be put down to differences of ability in applying the theory. However, differences between the performances of individuals with comparable intellectual abilities are sometimes best explained by appealing to differences of detail in what they believe about the mind. We often want to do this without saying that the individuals in question have different theories.

The Lakatosian view provides a natural way to allow for the possibility of small-scale differences in belief between individuals who share what is, broadly speaking, the same conception of the mind. It does this by drawing a distinction between the "core" of a research program and its other elements. This is a distinction which developmental theorists can appeal to when explaining differences 
in performance which are not to be plausibly explained as being the result of differences in individuals' abilities to apply one and the same theory, nor to their possession of different overall theories.

Despite this, one might think that Lakatos' views are unlikely to serve the deveopmentalist well. One reason for scepticism is Lakatos' view that if we want to understand what is distinctive about science we should focus on what he calls "research programs" rather than individual theories. The phrase "research program" conjures up a picture of a set of social practices and institutions which are characteristic of modern science, but which have no obvious analogue in the life of small children. As Gopnik and Meltzoff point out, children who are developing a grasp of folk psychology do not publish papers in scientific journals, attend conferences on the latest developments in their field of interest, or rely on the help of an army of graduate students and research assistants to help them formulate and test their hypotheses (Gopnik \& Meltzoff, 1997). Nor is someone putting forward the theory view likely to want to be committed to the idea that they do.

Convincing as these arguments against adopting a Lakatosian approach may seem, they will not do as they stand. As we shall see, Lakatos identifies research programs by appealing to structural features of the sets of claims which make them up and not to the nature of the social institutions in which they are embedded. So an advocate of the Lakatosian view might argue that these features of research programs are merely incidental to them: they do not explain what is distinctive about science, when science is conceived of as a truth-directed cognitive endeavour.

In what follows I shall be arguing that this strategy fails. It does so because we cannot separate out the structure of a Lakatosian research program from the social institutions which embody it in the way which the strategy requires. It should be emphasised that this is a claim that requires arguments. It cannot simply be assumed by someone who is hostile to using the Lakatosian framework in developmental psychology. The main goal of this paper is to make the necessary arguments explicit, defend them against objections, and draw out their implications for the use of the theory view in developmental psychology and elsewhere.

\section{Folk psychology as a Lakatosian research program}

In order to see whether a Lakatosian conception of theories is likely to be useful to researchers who are concerned with developmental issues we need to look at Lakatos' understanding of the term "research program" in some detail. According to Lakatos, a research program is a set of theories succeeding one another in time and sharing four elements. Lakatos calls these the core, the positive and negative heuristics, and the protective belt of the research program. The core of a research program is the central idea or theoretical insight on which it is based. One example often mentioned in expositions of Lakatos' views is that of Newton's three laws of motion. Others are Prout's hypothesis that the atomic weights of pure chemical elements are whole numbers and Bohr's postulates about the behaviour of the atom in early quantum mechanics (Lakatos, 1970a,b).

The positive and negative heuristics of the research program contain methodo- 
logical prescriptions about ways in which theories that constitute part of the same research program are to be modified. The negative heuristic says merely that the hard core of the research program should not be abandoned. The positive heuristic consists of a set of instructions for modifying the theory in the light of anomalous experimental results. This leads to the construction of what is referred to as a "protective belt " around the core of the theory. This protective belt shields the theory from immediate refutation by refractory experimental results.

In a 1996 paper entitled "Folk psychology and theoretical status," George Botterill (1996) has attempted to develop the idea that folk psychology is a Lakatosian research program. Botterill claims that at least part of the Lakatosian core of folk psychology can be found in the shape of the following three principles.

- Action Principle: an agent will act in such a way as to satisfy or at least to increase the likelihood of satisfaction of his or her current strongest desire in the light of his/her beliefs.

- Perception Principle: when an agent A attends to a situation $\mathrm{S}$ in a given way and $\mathrm{p}$ is a fact about $\mathrm{S}$ that is perceptually salient in that way, then $\mathrm{A}$ acquires the belief that $\mathrm{p}$.

- Inference Principle: when an agent $\mathrm{A}$ acquires the belief that $\mathrm{p}$ and a rational thinker ought to infer $\mathrm{q}$ from the conjunction of $\mathrm{p}$ with other beliefs that $\mathrm{A}$ has, A comes to believe that $q$.

Botterill is much less explicit when it comes to saying what the protective belt around these core principles consists of. But it may already be clear why he thinks that someone who takes folk psychology to be a theory should be attracted to the Lakatosian picture. For as he points out, it is difficult to imagine circumstances under which any of these principles might be given up. If the Lakatosian account of theories is correct, this fact does not, by itself, constitute an objection to the idea that folk psychology is a theory. It is precisely what we should expect if these principles are part of the core of a Lakatosian research program.

\section{Problems with the account}

There are many obvious differences between the social organisation which is characteristic of mature scientific research programs, and that which is characteristic of the life of young children. Any defender of the view that folk psychology develops in the same way as a scientific research program will have to be sensitive to this fact. As I have already suggested, the best strategy for someone defending this view is to say that these differences are beside the point. What is important on this view is whether the content of folk psychology is structured in the same sort of way as a scientific research program. If so, the question as to whether it is embedded in and transmitted by the same social structures as are typical of other scientific theories seems irrelevant.

We can now be more precise about what the claim about folk psychology's structure entails. For the strategy under consideration to succeed, we have to be able 
to find aspects of folk psychology which correspond to the notions of hard core, positive and negative heuristic and protective belt.

I shall now argue that this cannot be done. I have already pointed out that Botterill says very little about what might constitute the protective belt and positive heuristic of folk psychology. Now I shall try to show that this is not just an oversight on his part. We may be able to support Botterill's view by finding elements of a child's thinking about folk psychology which have the same role as the protective belt of a Lakatosian research program. However, there are difficulties of principle which stand in the way of finding anything that could be regarded as a positive heuristic for the child's conception of the mind.

This is a fatal objection to the attempt to model the child's conception of the mind on a Lakatosian research program. Having a core, a protective belt and a positive and negative heuristics are constitutive of being a research program (as Lakatos understands that term). Something that lacks one of these elements is not just a defective research program: it is not a research program at all.

In Lakatos' terminology, the protective belt of a research program is a set of supplementary hypotheses and theories which can be used to deflect criticism of its hard core. Botterill says nothing about what would play this role in the child's conception of the mind. However, at this point it is not difficult to fill in the gaps in his account. One obvious possibility is that the role of the protective belt might be played by specific hypotheses about the sorts of things that an individual might believe, desire, or find particularly salient on a given occasion. Another possibility might be thought of as a supplement rather than an alternative is this. The core principles which Botterill identifies could be viewed as giving an account of human performance under ideal circumstances, while the protective belt should contain descriptions of circumstances under which performance was liable to be less than optimal.

It is harder to see what might correspond to the positive heuristic of a Lakatosian research program. The positive heuristic is supposed to consist of a set of proposals for dealing with perceived anomalies within the particular theories which form part of a given research program. Furthermore, Lakatos' view appears to be that the positive heuristic of a research program should be capable of being specified in advance by participants in the research program. In other it has to be something more than the particular "bag of tricks" that scientists working on a given program happen to think of trying.

For example, in his case study of Bohr's work on early versions of quantum mechanics, Lakatos describes how the positive heuristic was "planned right at the start" with Bohr having in mind a series of more and more complex models of the behaviour of the atom. Furthermore, we can see why Lakatos should want to insist on the positive heuristic of a research program being specifiable in advance. For otherwise it is difficult to see how one could distinguish between a genuinely progressive research program, and a series of attempts to fix a theory by ad hoc tinkering that just happened to get lucky on a few occasions.

If we take this suggestion seriously, then it is obvious that there are going to be difficulties with finding something that corresponds to the role of a positive heuristic 
in the child's conception of the mind. The problem is not just that it is hard to establish what the positive heuristic might be until we have said more about the content of the protective belt. It is that Botterill's proposal does not give us any way of identifying a set of prespecified suggestions for modifying those beliefs in the light of recalcitrant evidence from the outside world. This would not matter if there $a$ priori reasons, or indeed strong a posteriori reasons based on evidence independent of the attractiveness of the Lakatosian picture, for thinking that such suggestions must exist. But, as I shall argue below, this is not the case.

Botterill's suggestion runs into difficulties because when we try to identify a set of positive heuristics for the child's theory of the mind the difference in sociological organisation between it and mature science makes a big difference. It is plausible to hope that we might be able to identify a Lakatosian positive heuristic in a mature science because the organisation of science is, in a sense, elitist. We have some idea that the leaders in any given branch of science are, and we can look to their pronouncements if we want to find out the direction in which the science should be going.

However, if we are interested in what is going on within the mind of an individual child [2], rather than within a branch of science as a whole, things are different. In this case, there is no obvious way of setting up a distinction between something that is a modification of the child's theory along lines suggested by a positive heuristic and something that is just a piece of ad hoc tinkering. If children were in a position to be fully articulate about the "research strategies" they were following matters might be different [3]. In fact, though, they are not. Furthermore, the sort of guided questioning which might realistically be though to be able to elicit a Lakatosian positive heuristic, if such existed in the mind of the child, would be highly suspect as a form of evidence. Whatever results it produced, they would be tainted with the possibility of being based on leading questions on the part of the investigator.

It might be argued that the points I have raised here relate the absence of evidence for the existence of something analogous to a positive heuristic in the child's theory of the mind. Absence of evidence is not the same as evidence of absence, however, and this might be thought to be a weakness in my argument. To this I want to make two replies. First, I have not just pointed out that there is no evidence in favour the existence of something analogous to a positive heuristic in the child's theory of the mind. I have also tried to show that there are principled difficulties in the way of finding such evidence.

Still it might be argued that I have only ruled out the possibility of direct evidence for a positive heuristic. This leaves open the possibility of finding good indirect evidence. The second part of my reply deals with this point. Of course it is much harder to rule out the possibility of finding indirect evidence for something than the possibility of finding direct evidence for it. So I shall restrict myself to arguing that at least at present we do not have good indirect evidence for the existence of something analogous to a positive heuristic either.

One piece of alleged indirect evidence that a defender of the Lakatosian picture might point to is this. Most human beings end up with roughly the same folk 
psychology, and do so as a result of going through more or less the same developmental stages. One might think that this shows that the way in which the folk psychologies of different individuals develop must be constrained by something. Furthermore, what does the constraining must also influence the way in which they react to apparently anomalous experiences. If so, it might be said, this something is what is analogous to a Lakatosian positive heuristic.

However, this line of argument does not constitute an adequate defence of the Lakatosian picture of folk psychology. It does not follow from the fact that psychological development must be constrained by something that what is doing the constraining must be analogous to a Lakatosian positive heuristic. For example, it might be that the constraints here were partially or wholly innate. If so it is difficult to see how they could be integrated into a picture on which folk psychology was analogous to a Lakatosian research program. Alternatively the constraints might derive from the nature of the data with which children are presented: these might be such as to make the development of folk psychology in some directions more straightforward than in others. Unless these possibilities are ruled out, or at least argued against, the Lakatosian picture is under-supported.

Furthermore, if the only reason for adopting the Lakatosian picture is that folk psychological theorising must be constrained in some way, then the proposed analogy between folk psychology and Lakatosian research programs appears particularly weak. One apparent strength of the analogy was that it is supposed to be able to cast some light on the way in which folk psychology develops. This promise can only be made good if we can find something in folk psychology that is analogous to the Lakatosian positive heuristic. This is because on a Lakatosian view it is the content of the positive heuristic that explains why a scientific research program develops in one way rather than another. So on pain of explanatory vacuity we need to be able to say something explicit about the content of the positive heuristic: we cannot just say that it is whatever causes a child's conception of the mind to develop in one way rather than another.

I have argued at length that there is no reason for thinking that the child's theory of the mind has anything corresponding to a Lakatosian positive heuristic. One response would be to argue that most research programs that belong to bona fide sciences do not have anything like a Lakatosian positive heuristic either. At any rate, it might be said, this is true if the positive heuristic is conceived of as something that has to be capable of being specified before the theories of the research program have been confronted with actual anomalies. In other words the requirement that a scientific research program in good standing should possess this feature is far too stringent.

There are two ways in which this line could be developed. One is to say that there is just nothing like a positive heuristics to be found in the development of scientific theories. Another is to argue that positive heuristics are not present in the minds of scientists working on particular research programs but are discovered retrospectively by historians.

Tempting as these ideas may be, neither of them is much help to someone defending the position which is under attack in this paper. Someone who takes the 
first line is objecting to an important feature of Lakatos' philosophy of science. So the force of the objection is not that folk psychology is more like science than I have made it out to be. It is that science does not have the features that Lakatos takes it to have. Although this may constitute a defence of the theory theory, broadly conceived, it is of no use in defending the idea that folk psychology is a theory insofar as it has the structure of a Lakatosian research program. And it still leaves the defender of the theory view with the job of providing us with a characterisation of the nature of theories.

Someone might argue that the second line is more helpful. Lakatos has often been accused of rewriting episodes in the history of science in line with rational reconstructions of what its history ought to have been instead of the concerns that have motivated actual scientists. So it might be suggested (only slightly tongue in cheek) that despite what he says about Bohr, we should rationally reconstruct Lakatos' own view. According to the rational reconstruction we shouldn't be looking for positive heuristics in the mind of the scientists. Instead they are discovered by those who try to impose some narrative coherence on the messy business of science after the event.

However, although this might be a defensible account of the historiography of science it does not help the developmentalist much. First, the developmentalist is in the business of explaining the development of the child's conception of the mind, not merely describing it. It is difficult to see how a positive heuristic that was not available to the child but only to someone describing the child's development after the event could have much explanatory power.

Even if the psychologist were just in the business of describing change without explaining it, there would be something very mysterious about the idea under consideration. It would be tantamount to the claim that the child's conception of the mind develops as if under the guidance of a positive heuristic, which only really exists in the eye of the describing psychologist. This would be a form of instrumentalism. Like many forms of instrumentalism it is unsatisfactory: typically we want to know what mechanisms sustain the regularity which the instrumentalist claims only to be able to describe. Instrumentalism is most successful when this question can be ruled out as illegitimate. However, there is no reason for thinking that this can be done when we are discussing the ways in which the child's theory of the mind develops.

\section{Some morals for developmental psychology}

My argument in this paper has not been directed at the theory view of folk psychology as such. There may be ways of articulating that view which are entirely unobjectionable, and which may indeed provide an interesting basis for future research. Indeed we should hope that this is true. Questions about the development of psychological concepts in small children are both intrinsically interesting, and seem likely to have a significant bearing on a number of important philosophical issues. The theory view provides an interesting umbrella hypothesis, which has led 
to the discovery of some intriguing phenomena, and seems likely to continue to do so in future.

That said, most advocates of the theory view need to say much more about what the claim that folk psychology is a theory actually amounts to. Furthermore, one way of fleshing out this view which is likely to seem particularly attractive to those advocates of the theory view who are interested in applying it to developmental issues-namely, by drawing an analogy between folk psychology and scientific theories as conceived of by Lakatosians - turns out to be unacceptable. It would be useful to be able to say more than this. In particular, it would be useful to be able to explain why this particular attempt at giving substance to the theory view has been unsuccessful. Such an explanation might suggest how someone who wanted to defend the theory view by giving a more explicit account of the nature of theories might be able to proceed. I shall conclude my paper by considering three possible explanations, and their implications.

One explanation would be to say that anyone who explains the theory view in terms drawn from the philosophy of science is seriously missing the point. Someone who took this view might appeal to Chomskyan explanations of our mastery of grammar, and argue that the notion of a tacit theory that is embodied in this research program is the appropriate one for the advocate of the theory view to rely on. (This view is suggested in Davies and Stone, 1995, and discussed critically in Carruthers, 1996.)However, this is a mistake. There is an important disanalogy between the explanatory work that the notion of theory is doing within the context of the Chomskyan program and the work that it is doing in the context of the theory view of folk psychology. In the latter context the notion of a theory can help to illuminate the way in which folk psychological knowledge develops. It does so by drawing on our knowledge of the way in which scientific theories develop. This is precisely what seems so appealing about the use of Lakatos' work: his philosophy of science contains an important developmental element. Within the Chomskyan program, appeal to the notion of theory plays a different role. The Chomskyan account points to our knowledge of a grammatical theory to explain the development of our linguistic capacities. However, in this case our knowledge of a theory is supposed to explain the fact that when we learn a language what we learn goes beyond the input given. It does not explain the way in which one stage of linguistic development leads on to another. In other words the sorts of innate theories which are appealed to in the Chomskyan program are static-they do not develop in the way in which the child's theory of the mind is supposed to develop.

A more interesting explanation of the failure of the Lakatosian construal of the theory view is that Lakatos' account of science is unsuitable for developmental purposes because of his interest in epistemological issues. The thought here would be that an advocate of the theory view of folk psychology should make a sharp distinction between the project of describing folk psychology and the project of vindicating it. However, Lakatos' approach to the philosophy of science, it might be said, makes these two issues difficult to keep apart. Lakatosian descriptions of the structure of scientific research programs are motivated at least in part by a concern with vindicating what we regard, prior to the description as our favourite examples 
of good science. If we are interested primarily in developmental issues, then the Lakatosian concern with vindicating particular research programs is likely to seem out of place.

This diagnosis seems more appealing than the one previously suggested. However, it is not the full story. Many Lakatosians would deny that their account of science makes it impossible for them to distinguish between the project of describing something as science and that of vindicating particular pieces of scientific practice. Admittedly, given Lakatos' views about how the philosophy of science ought to be done, we have to be able to identify paradigmatic examples of good science before we can give an adequate account of scientific methodology. Still, there is no obvious reason why we cannot apply what we have learnt from studying paradigmatic examples of good science to judge whether particular instances of scientific theories constitute good or bad science on the basis of what we have learnt from our study of the paradigms. Of course, important issues will arise when an apparently acceptable scientific theory turns out to violate the methodological prescriptions that we have derived from a study of our favourite examples of past practice. But this is not an issue which only Lakatosians have to face: it is the sort of problem that is liable to be faced by anyone who is engaged in any kind of normative epistemology.

However, although Lakatos' interest in epistemological questions does not explain why this approach to articulating the theory view is unsuccessful, some features of his approach to epistemology are relevant. Lakatos' philosophy of science is highly anti-individualistic: his concern is primarily with whether it is rational for a society as a whole to accept a scientific theory at a given time and not with whether it is rational for individual scientists to do so. This anti-individualis $m$ is not an aspect of his approach which is easily eliminable: as I have argued, identifying the features which research programs are supposed to have forces us to take into account the social organisation of science.

It may well be that such an approach to the philosophy of science is entirely appropriate: scientific ideas do to some extent appear to have a life of their own-a life which is embodied in institutions and contexts which are only partially constituted by the individuals who make them up. If so there may be a deeper lesson to be drawn. For at least some recent advocates of the theory view have hoped that whichever account of scientific theories is correct the theory view will allow us to learn lessons about developmental psychology by studying philosophy of science (Gopnik, 1996; Gopnik \& Meltzoff, 1997).

Gopnik and Meltzoff's account of children's development focuses very narrowly on the ways in which individual children's cognitive capacities develop through their confrontations with their environment. They have relatively little to say about the ways in which children's acquisition of theories about the mind might depend upon their interaction with other individuals, except insofar as these other individuals form part of the environment on which they can test their theories. Of course, there is a good rationale for this individualistic focus. It is reasonable to expect that a child's ability to learn from other people will be constrained in important ways by their grasp of a theory of the mind. So we need to be very cautious about 
forming hypotheses about the ways in which children's developing grasp of a particular subject matter might depend on their interaction with others. Otherwise we run the danger of putting forward developmental models which assume that children have some of the intellectual capacities whose appearance we are trying to explain.

However, this raises an important problem. It is arguable that the best contemporary accounts of science are ones which, like the Lakatosian account we have been looking at, stress its social nature. If so then it is unlikely that we will be able to learn much about developmental psychology from the philosophy of science while observing individualist constraints on psychological theorising. In that case we have two options open to us. One is to abandon the project of trying to apply lessons from the philosophy of science to developmental psychology. The other is to abandon the individualistic constraint that advocates of such accounts tend to accept. Whether a workable version of the theory view could be worked out if this constraint were dropped is not clear. What is clear is that it would be radically different from those versions of the theory view which have been on offer in developmental psychology so far [4].

\section{The epistemological status of folk psychology}

For most of this paper, I have been considering ways in which a Lakatosian view of folk psychology might be used in developmental psychology. The main purpose of the paper has been to show that despite the apparent attractions of this view-which I have argued to be non-negligible-we should not accept it. However, as I remarked in my introduction, the theory view of folk psychology has been put to other uses as well. One of them is arguing for the eliminativist view that folk psychology is an epistemologically inadequate theory which ought to be discarded. It is natural to wonder whether the arguments I have put forward have any impact on this debate.

Although this claim is subsidiary to my main line of argument, I think that they do. In this section I shall explain why. My reason for doing so is that although there are important differences between how eliminativists conceive of folk psychology and how developmental psychologists conceive of it, some of the argumentative claims that need to be made in objecting to the two views run parallel to one another. However, one limitation on the significance of the claims I shall be making in this section needs to be made explicit. The points I shall make are only addressed to one particular version of an argument for eliminativism which is based on the theory view: one which tries to show that folk psychology should be discarded because it is a stagnating Lakatosian research program. They leave other arguments for eliminativism untouched.

The argument I shall be addressing is best represented by Paul Churchland (1979, 1981). Churchland's early presentations of his argument for eliminativism are couched in terms that certainly sound Lakatosian. Lakatos uses his account of scientific research programs to answer normative questions about what views scientists ought to accept and claims that research programs which "stagnate" should be discarded. For a research program to stagnate, in Lakatos' terms, is for it to fail to 
produce new theories along lines suggested by the positive heuristic which account for discrepancies between their predecessors' predictions and actual observations. In some of his early work Churchland might be read as claiming that folk psychology is stagnant in precisely this respect [5].

It might seem obvious that the points that I have made so far leave this argument untouched. I have claimed that an individual's grasp of folk psychology does not have the structure of a Lakatosian research program. However, someone arguing for eliminativism on the basis of a comparison between folk psychology and a Lakatosian research program would probably rest their case on the claim that our species as a whole has a grasp of folk psychology which does meet the Lakatosian model. As they stand, my arguments do not address this claim.

Still, some of the points that I have made in my discussion of Botterill's view turn out to be relevant to Churchland's position as well. My central claims were that we do not something appropriately analogous to a Lakatosian research program unless we identify its positive heuristic; and that in order to identify a positive heuristic we need something approximating to the sociological structure of science. Since folk psychology does not have this structure it does not have a positive heuristic. So it is not a Lakatosian research program. A fortiori it is not a stagnating Lakatosian research program. This point holds even if we think of folk psychology as a cultural rather than an individual possession.

To get round this problem, the eliminativist needs to argue that differences between the sociological organisation of science and that of folk psychology are less great than they seem at first sight. For example, she might argue that academic psychologists play the role of a folk psychological elite. If so, their responses to problems posed by counter-intuitive results in experiments such as the Wason selection test can be cast in the role of the positive heuristic of a Lakatosian research program.

Although this suggestion might preserve the essentials of the idea that folk psychology is a Lakatosian research program, it somewhat undermines the serviceability of relying on that claim in arguing for an eliminativist conclusion. For psychology has only existed as an academic discipline for a relatively short time, and so on this construal folk psychology has only become a research program in the relatively recent past (Fancher, 1996). If so then it has certainly not been stagnating for two thousand years.

The eliminativist might concede this but deny its significance. Even if folk psychology has only been stagnating for two hundred years rather than two thousand, it is still in trouble. After all, most scientific research programs have a much shorter life than this-20 years at most.

This is too quick, though. One thing that it overlooks is the phrase "research program" is used as a technical term by Lakatos. As Hacking points out (Hacking, 1983), it does not have the same extension as the term when used by grant administrators and deans of university science faculties. The former is

a specific attack on a problem using some well-defined combination of theoretical and experimental ideas ... A program of research which a per- 
son or group can undertake, seek funding for, obtain help with and so on ... (pp. 115-116)

whereas the latter

$\ldots$ is not much like that ... It is a sequence of developing theories which might last for centuries, and might sink into oblivion for eighty years and be revived ... (p. 116) [6]

Hacking's point is confirmed by the sorts of things which Lakatos calls research programs. For example he discusses at great length the so-called "Copernican" and "Ptolemaic" research programs, neither of which could be regarded as research programs except in the technical sense which he introduces (and which I have discussed in detail above.)

The upshot of this is that if we are judging folk psychology by Lakatosian criteria our conclusions about whether we ought to discard it cannot be based on our intuitions about the careers of contemporary scientists. We need to compare folk psychology with research programs like Copernicus', not with the funding criteria of the Department of Defence.

Furthermore, if we allow that the positive heuristic for folk psychology is set by the community of academic psychologists, then it is not obvious that folk psychology is stagnating at all. In fact, in Lakatos' terms it appears to be both empirically and theoretically progressive. It is theoretically progressive (in Lakatosian terms) because psychologists do produce theories that make predictions that are different from those of their predecessors. It is empirically progressive because at least some of these theories are confirmed. Crucially for our purposes, this is all that Lakatos requires for a program not to count as degenerating or stagnating.

Nor is it to the point to claim that folk psychology (as conceived of under the current interpretation) has some longstanding anomalies. One reason why Lakatos frames his criteria for progress and stagnation in the way in which he does is that he wants to allow for the possibility that a scientific theory in good standing may nevertheless make some predictions which are falsified. What counts for Lakatos is the track record of the scientific research program to which a theory belongs. Lakatos frames his account in these terms because he wishes to accommodate the claim that good theories are often "born falsified." It may be that he is wrong to do so; but the point remains that if we are judging folk psychology by Lakatosian criteria then the existence of longstanding anomalies is not, by itself, evidence of stagnation.

Finally, it is also irrelevant to point to a long period of stagnation before the birth of modern academic psychology as evidence for the stagnation of folk psychology. Suppose we concede that before the birth of scientific psychology, folk psychology was a fully blown Lakatosian research program in which non-scientists, such as poets, priests or shamans, were responsible for defining the positive heuristic [7], and that during this period it did stagnate. It does not follow that we should abandon folk psychology now. If we are relying on Lakatosian criteria, what matters is whether folk psychology is stagnating now. As has been remarked before (Hack- 
ing, 1983, pp. 116, 120), Lakatos' account leaves open the possibility that an a research program which has stagnated for some time may suddenly become progressive, and that if so we should be more impressed by the latter fact than the former. To the objection that this means that it might now be rational for us to accept theories which we only have because we were not equally rational in the past, a fully convinced Lakatosian would reply that this is one of the ironies of scientific history.

In short, even if we accept that folk psychology can be regarded as a Lakatosian research program (a claim which, I should emphasise, I am conceding only for the sake of argument), we can make a good case for regarding it as progressive rather than degenerating. This means that an eliminativist cannot rely on a Lakatosian account of science to arrive at an eliminativist conclusion.

\section{Concluding remarks}

The view that our common-sense conception of the mind is a theory has been put to many uses. But what the consequences of that view are will depend on what we take scientific theories to be. I have argued that one apparently attractive view of scientific theories-the Lakatosian view-has significant implications for two important debates. It makes the idea that children's conception of the mind is a theory harder, not easier, to defend; and it makes eliminativism about common-sense mental state concepts less, not more, attractive.

Of course, those who want to defend one or other of these views are not left without argumentative recourse: they can repudiate the Lakatosian account of theories. However, they need to do two other things as well. One is to put forward a viable account of the nature of theories. The second is to show that it has the consequences that they take it to have. One moral of my discussion is that this may be harder to do than it seems at first sight: apparently attractive accounts may, like the Lakatosian view, have hidden pitfalls for both developmentalists and eliminativists.

A second, wider, moral is this. Accounts of science which stress the way in which science is dependent on specific kinds of social structure are unlikely to provide much help either to eliminativists or to people who think that the child's theory of the mind develops in the same way as a scientific theory. However, some philosophers of science have come to suspect (Hull, 1988; Kitcher, 1993) these are the best accounts of science that are currently available. If so, then the idea that our understanding of the child's conception of the mind can be advanced by learning lessons from the philosophy of science may turn out to be a dead end. So, perhaps less surprisingly, may eliminative materialism.

\section{Acknowledgements}

I would like to thank Cees van Leeuwen and two anonymous referees for helpful comments on earlier drafts. 


\section{Notes}

[1] Gopnik and Meltzoff (1997) constitute a rare exception to this generalisation. For critical discussion of their account, see Stich and Nicholls (1998) and Schwitzgebel (1999). My view is that Gopnik and Meltzoff's view is too strict to be a good characterisation of theoryhood in general (as Schwitzgebel claims) and too liberal to count as a characterisation of scientific theoryhood. I hope to write further about this issue in future work.

[2] I am assuming here that developmental psychology has to be individualistic. As one referee has pointed out, it isn't always: work in the Vygotskyan tradition, and in particular recent work by Barbara Rogoff and Chikako Toma (e.g. 1997) and Mary Gauvain (e.g. 1998, 2001), provides a counterexample. However, advocates of the theory view in developmental psychology have tended to be individualist in orientation. I discuss some reasons for this in the last section of my paper. Whether a Lakatosian (or any other) version of the theory view could survive if purged of its individualist features, I am not sure. One obvious difficulty is that the Lakatosian accounts of science (and other accounts that one might want to appeal to) are likely to presuppose that scientific enquirers can depend on their possession of a mature folk psychology when trying to make sense of the activities of their co-workers.

[3] In fact it is not clear how different they would be. There would still be important questions to be asked about whether what they were doing was giving an accurate report of their thought processes, or confabulating a coherent narrative.

[4] See note 2 for some reasons for thinking that such an account is unlikely to be Lakatosian in nature. I am inclined to think that similar doubts would apply to more recent accounts which stress the social nature of science, such as those put forward by Hull (1988) and Kitcher (1993). But to show this would take me beyond the confines of the present paper.

[5] Of course it may be that the Lakatosian reading of these remarks is not intended and that the claim that folk psychology is a stagnating research program is intended in a much looser sense. If so, though, someone who wishes to rely on it needs to provide some characterisation of what he or she takes a scientific research program to be and an argument that folk psychology fits that characterisation.

[6] It is worth underlining that Hacking is talking about Lakatosian research programs in general here, and not specifically about failing ones.

[7] Incidentally this claim seems to rely on a large amount of armchair anthropology and sociology which a good empiricist like Churchland ought to eschew.

\section{References}

Botterill, G. (1996). Folk psychology and theoretical status. In P. CARrUthers \& P.K. SMITH (Eds) Theories of theories of mind. Cambridge: University Press Cambridge.

CARruthers, P. (1996). Simulation and self-knowledge-a defence of the theory theory. In P. CARRUTHERS \& P.K. SMITH (Eds) Theories of theories of mind. Cambridge: University Press Cambridge.

ChurChland, P.M (1979). Scientific realism and the plasticity of mind. Cambridge: Cambridge University Press.

Churchland, P.M. (1981). Eliminative materialism and the propositional attitudes. Fournal of Philosophy, 78, 67-81.

Davies, M. \& STONE, T. (1995). Folk psychology—the theory of mind debate. Oxford: Blackwell.

FANCHER, R. (1996). Pioneers of psychology. New York: Norton.

FEYerabend, P. (1963). Materialism and the mind body problem. Review of Metaphysics, 17, 49-68.

GauvaIn, M. (1998). Cognitive development in social and cultural context. Current Directions in Psychological Science, 7, 188-192,

Gauvain, M. (2001). Cultural tools, social interaction, and the development of thinking. Human Development, 44, 126-143.

GopNIK A. (1996).The scientist as child. Philosophy of Science, 63, 485-514.

GopniK, A. \& MELTzoff, A. (1997). Words thoughts and theories. Oxford: Blackwell. 
HaCKING, I. (1983). Representing and intervening. Cambridge: Cambridge University Press.

Hull, D. (1988). Science as a process. Chicago: University of Chicago Press.

KITCHeR, P. (1993). The advancement of science. New York: Oxford University Press.

LAKatos, I. (1970a). Falsificationism and the methodology of scientific research programs. In I. LaKatos \& A. Musgrave (Eds) Criticism and the growth of knowledge. Cambridge: Cambridge University Press.

Lakatos, I. (1970b). Philosophical papers volume I: the methodology of scientific research programs. Cambridge: Cambridge University Press.

Lewis, D. (1967). How to define theoretical terms. Fournal of Philosophy, 63, 17-25.

LEWIS, D. (1970). Psychophysical and theoretical identifications. Australian fournal of Philosophy, 50, 249-58.

Poulin-Dubois, D. (1998). Sailing in Neurath's boat with infants (and avoiding shipwreck). Mind and Language, 13, 415-420.

Rogoff, B. \& TomA, C. (1997). Shared thinking: community and institutional variations. Discourse Processes, 23, 471-497.

RorTy, R. (1965). Mind-body identity, privacy and categories. Review of Metaphysics, 19, 49-66.

Schwitzgebel, E. (1999). Children's theories and the drive to explain. Science and Education, 8, $457-488$.

STICH, S. \& Nicholls, S. (1998). Theory theory to the max: a critical review of Gopnik and Meltzoff's "Words thoughts and theories." Mind and Language, 13, 421-449. 